\title{
Covid-19: Hong Kong government supplies reusable face masks to all residents
}

\author{
Jane Parry \\ Hamilton, Canada
}

The Hong Kong government has begun to distribute reusable face masks to all residents, as part of its strategy to protect the city's 7.5 million people from covid-19. ${ }^{1}$ In addition, all households will be supplied with 10 single use surgical masks, 30 million in total, in late June.

The CuMask+ was developed by the Hong Kong Research Institute of Textiles and Apparel and is manufactured locally and in Vietnam. It has six layers, two infused with copper, which is capable of immobilising bacteria, common viruses, and other harmful substances. The name refers to the chemical symbol for copper and is a play on the words "see you."

On the first day of online registration for the mask, there were 2 million registrants. ${ }^{3}$ Primary school and kindergarten children will each receive two child sized masks when schools resume and masks will also be distributed to residential homes and social welfare agencies.

Since 23 January when the first cases of covid-19 were confirmed, Hong Kong has been relatively successful in containing the epidemic. Despite the city's proximity to mainland China and its extreme population density, as of 6 May there have been only four deaths and 1044 confirmed cases, and no locally acquired cases for 18 consecutive days. This has been attributed to a combination of border control and social distancing measures, aggressive testing, contact tracing, and mandatory quarantine, and the early and widespread adoption of personal protective behaviours by the population. ${ }^{4}$

Even before the government began to introduce measures to combat the disease, wearing a surgical mask became an almost ubiquitous practice in Hong Kong as soon as news of a SARS like outbreak across the border in China reached the city in early January. ${ }^{5}$ Surveys of the population found that by 23 January, $74.5 \%$ of respondents wore face masks in public, and the figure was up to $99 \%$ within three weeks of the outbreak starting. ${ }^{67}$

Over the past three months there have been border closures, social distancing measures including school closures, periods of work from home orders for civil servants, and the closure of public leisure facilities and some venues such as cinemas and bars, but the city has not been under the severe lockdown measures imposed in many western countries. Shops, restaurants, and businesses have remained open throughout. People are free to move about and can gather in groups of eight or less from 8 May onwards, up from a four person limit imposed in early March.
The concomitant drastic decline in the number of people affected by influenza like illness and other respiratory tract infections during the pandemic period indicates sustained personal protective measures have helped reduce local transmission significantly. "The number of laboratory confirmed cases of influenza in Hong Kong is virtually zero in the past two months," said Ho Pak Leung, president of the Carol Yu Centre of Infection at the University of Hong Kong.

As soon as the CuMask+ initiative was revealed, it drew widespread negative reactions on social and mainstream media, ranging from mockery of the name and similarity of the fabric choice to that used to make men's underwear, ${ }^{9}$ criticism of the opaque procurement process, and suspicion about the purpose of the data collection process during registration. ${ }^{10}$

"We Hong Kongers don't have a lot of trust in our government and whatever they do will be under a lot of scrutiny," said Tim Wong Lok-yu, a doctor in the emergency department in one of Hong Kong's public hospitals.

"This is a dubious scheme, given that in Hong Kong people are not in dire need of masks, the supply is stable, prices are falling, and we are emerging from the pandemic, not in the middle of it," he said.

Ho said that other countries should learn from the example of Hong Kong and its east Asian neighbours. "The virus is spreading all over the world, and we can see in areas that use mass masking as public health policy-Hong Kong, Macau, mainland China, Japan, and South Korea-it is clearly working. Even if putting on a mask is only $50 \%$ effective for individual protection, if everybody does it, it will be close to $100 \%$ effective."

1 Government of the Hong Kong Special Administrative Region. Government to distribute free reusable masks to all citizens. May 2020. www.info.gov.hk/gia/general/202005/05/ P2020050500692.htm.

2 CuMask+. www.qmask.gov.hk

3 Government of the Hong Kong Special Administrative Region. 2m registered for CuMask. May 2020. www.news.gov.hk/eng/2020/05/20200507/20200507_132114_106.html

Wong SYS, Kin On K, Chan FKL. What can countries learn from Hong Kong's response to the COVID-19 pandemic?CMAJ 2020;cmaj.200563. 10/1503/cmaj.200563. 32332040

5 Parr J. Pneumonia in China: lack of information raises concerns among Hong Kong health workers. BMJ 2020;368:m56. 10.1136/bmj.m56 31915179

6 Cowling BJ, Ali ST, Ng TWY, et al. Impact assessment of non-pharmaceutical interventions against coronavirus disease 2019 and influenza in Hong Kong: an observational study. Lancet Public Health, 2020;S2468-2667(20)30090-6.pmid:32311320.

7 Kwok KO, Li KK, Chan HHH, et al. Community responses during early phase of covid-19 epidemic, Hong Kong. Emerg Infect Dis 2020;26. 10.3201/eid2607.200500. 32298227

8 Chan KH, Lee PW, Chan CY, Lam KBH, Ho PL. Monitoring respiratory infections in covid-19 epidemics. BMJ 2020;369:m1628. 10.1136/bmj.m1628 32366507

9 Xiang L. Cu mask: the cloth across the mask is pointed like underpants. www.hk01.com \%E7\%86\%B1\%E7\%88\%86\%E8\%A9\%B1\%E9\%A1\%8C/469716/cu-mask-\%E5\%8F\% A3\%E7\%BD\%A9\%E6\%A9\%AB\%E9\%96\%93\%E5\%B8\%83\%E6\%96\%99\%E8\%A2\% 
AB\%E6\%8C\%87\%E4\%BC\%BC\%E5\%BA\%95\%E8\%A4\%B2-\%E7\%B6\%B2\%E6\%B0\% 91-fashion\%E5\%98\%85\%E5\%98\%A2

10 Ho K. Coronavirus: Hong Kong gov't reveals producers of giveaway masks, as applicants raise privacy concerns. Hong Kong Free Press. May 2020. https://hongkongfp.com/2020/ 05/07/coronavirus-hong-kong-govt-reveals-producers-of-giveaway-masks-as-applicantsraise-privacy-concerns.

Published by the BMJ Publishing Group Limited. For permission to use (where not already granted under a licence) please go to http://group.bmj.com/group/rights-licensing/ permissions 